\title{
End-of-life scenarios of membrane structures: is circularity an option?
}

\author{
M. Mollaert, G. Sonmez, M. Van Craenenbroeck and L. De Laet
}

Architectural Engineering, Vrije Universiteit Brussel, Pleinlaan 2, 1050 Brussels, Belgium

e-mail: marijke.mollaert@vub.be,web page: www.vub.be

Tensioned membranes structures are built on any scale and can be used for many functions. In the majority, they are stationary and 'permanent' like for Stadiums, but they can also be temporary or even mobile like for Fairs or Expo's. The life expectancy of coated fabrics is 20 to 40 years, for ETFE foils more than 100 years.

This paper considers, by means of analysing case studies, the environmental performance of membrane structures. 'Circularity' in use and current options at the end-of-life phase are evaluated. Most information has been obtained by means of interviews.

The Elspe Grandstand cover (Fig. 1, Left) is an open canopy (77m long, $\sim 36 \mathrm{~m}$ wide, self-weight $13 \mathrm{~kg} / \mathrm{m}^{2}$ ), hanging on 2 main cables. The structure was built in 1978 and the membrane replaced in 2014. The primary structure is reused, without major modifications, and will support the new roof for another 40 years. The old membrane was 'thrown away', which is not the most eco-friendly solution.

The Finmeccanica Pavilion (Fig. 1, right, triangular plan: $34.6 \mathrm{~m}$ wide, $49 \mathrm{~m}$ long, self-weight $50 \mathrm{~kg} / \mathrm{m}^{2}$ ) was built in spring 2006 for the International Air Show (Farnborough, UK). After four weeks, the construction was dismantled and stored. The pavilion was reused in 2008, in 2010, and in a different set-up in 2013 in Le Bourget (Paris, FR). The self-supporting steel construction and membrane material were therefore made removable. The steel frame is still good and could be reused in future. What happened with the membrane and foils is unknown.

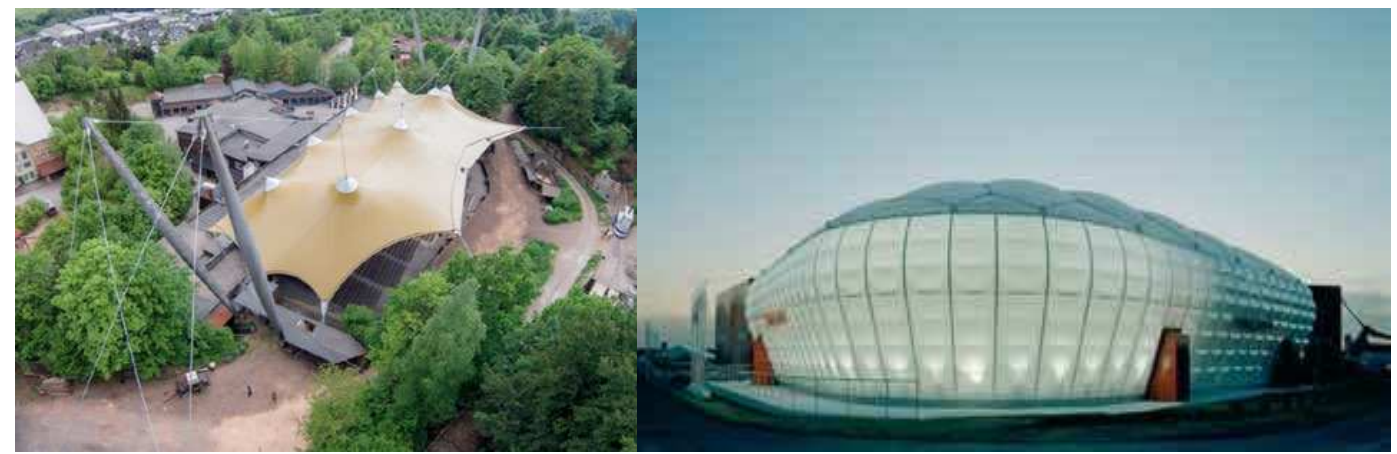

Fig. 1. Left: The new Elspe Grandstand Roof (C) Koch Membranen, right: The Finmeccanica Pavilion (C) form TL

The dismantling in 2014 of the temporary membrane roof of the London Olympic Stadium (Fig. 2, Left, 310m x $260 \mathrm{~m}$; width $\sim 35 \mathrm{~m}$ ) was done carefully, separating components which could be reused or recycled. The $33000 \mathrm{~m}^{2}$ of Précontraint ${ }^{\circledR} 1202$ S2 was recycled in the Texyloop ${ }^{\circledR}$ plant, at that time still operational. Nonwoven polyester material was produced, which was implemented as a filtration layer in the green roof (total area of $1270 \mathrm{~m}^{2}$ ) of Firminy's General Hospital. Considering the coated membrane, recycling means a reduction of the environment impacts by about $50 \%$, compared to incineration or landfill.

At the Vadofone project (Fig. 2, right, $270 \mathrm{~m}^{2}$, Newbury, UK) the ETFE cushions in the roof, installed in 2001, have been replaced in 2020, with the primary structure being reused. ETFE is $100 \%$ recyclable. Vector Foiltec takes back all old material to recycle it, and purchases flexible pipes and valves made from recycled ETFE.

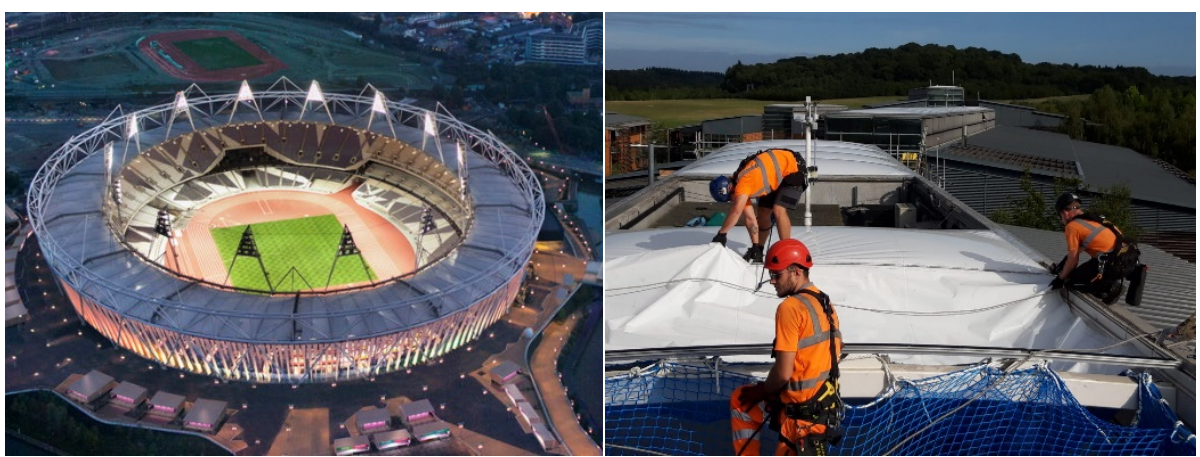

Fig. 2. Left: London Olympic Stadium, 2012@C Populous, right: Dismantling ETFE foils, Vodafone project (C) Vector Foiltec

Different projects illustrate different approaches, which could support the eco-design of membrane structures. Effort should be made to increase the recycling possibilities of coated fabrics and foils. It should be possible to quantify the benefits of recycling, to help to overcome the inconveniences which make owners today prefer to incinerate used membranes or to bury them in landfill. 